\title{
EFFECT OF ANIMAL FATS ON THE PHYSICAL PROPERTIES OF PALM FAT
}

\author{
A. Soós ${ }^{a *}$, Cs. PecznyiK ${ }^{\mathrm{a}}$, L. Somogyi ${ }^{\mathrm{a}}$ and I. Zeke ${ }^{\mathrm{b}}$ \\ a Department of Grain and Industrial Crop Technology, Faculty of Food Science, Corvinus University of Budapest, \\ H-1118 Budapest, Villányi út 29-43. Hungary \\ ${ }^{\mathrm{b}}$ Department of Refrigeration and Livestock Products Technologies, Faculty of Food Science, Corvinus University \\ of Budapest, H-1118 Budapest, Ménesi út 43-45. Hungary
}

(Received: 25 February 2013; accepted: 13 September 2013)

\begin{abstract}
Palm fat is one of the most commonly used fats in food industry. The main role of palm fat is to develop the desired texture of food products. Fat blends were developed to find the most appropriate mixture fitting the technological needs. In our work palm mid fraction (PMF) was mixed with anhydrous milk fat (AMF), goose fat (G), and lard (L) in a 1:1 ratio. Anhydrous milk fat represents fat consisting of a wide range of fatty acids. Goose fat is a soft, easily melting fat, and lard is characterized as animal fat with wide melting temperature interval. The measurements aimed to establish the miscibility of the fats and the effect of animal fats on the melting-solidification profile of palm mid fraction. SFC vs temperature curves, Differential Scanning Calorimetry (DSC) melting thermograms describe the melting profile of the samples. Isotherm crystallization by SFC vs time curves and DSC cooling thermograms were measured to characterize the solidification of pure fats and the blends. Since the SFC curves did not show crosspoints we concluded that fats blended in a 1:1 ratio were miscible. Anhydrous milk fat strongly modified the properties of palm mid fraction, the blend became similar to anhydrous milk fat. Goose fat had no strong modification effect on palm mid fraction and could be considered as a softening agent. The effect of lard was complex: melting and solidification behaviour of the blend differed from the characteristics of both parent fats.
\end{abstract}

Keywords: palm fat, solidification, melting, DSC, solid fat content, fat blends, animal fats

Fat mixtures are in the focus of recent technological research (MING et al., 1999; BRAIPSONDanthine \& Deroanne, 2004; Bell et al., 2007). Although mixtures of butterfat or milk fat had been investigated (LIEw et al., 2001; SINGH et al., 2004), there is only little information available on the role of the effect of fats of animal origin in technological feasibility (JIN et al., 2008). Fats should modify the physical properties of any vegetable fat in different ways (e.g: Danthine, 2012).

The most important points are the melting profile and solidification. The former is generally described by the solid fat content (SFC) curves, which are a function of the solid percent of the fat vs temperature as well as the melting thermogram that is measured by DSC for heating scenario. Solidification should be studied by NMR technique to establish the isotherm crystallization and DSC thermogram for cooling scenario.

In our research PMF was used as a vegetable fat, mixed with AMF, L, and G. The aim of the work was to establish the effect of blending PMF with animal fats on melting and solidification characters of the obtained blends. The blends are to be utilized in bakeries as shortenings and in preparing spreads.

\footnotetext{
* To whom correspondence should be addressed.

Phone: +36(1)482-6345; fax: +36(1)482-6355; e-mail: anita.soos@uni-corvinus.hu
} 


\section{Materials and methods}

\subsection{Materials}

PMF, AMF, G, and L were collected directly from firms of the local industry (Bonbonetti Choco Ltd. Budapest) and from the local market. Of the materials $500 \mathrm{~cm}^{3}$ was heated up to $80{ }^{\circ} \mathrm{C}$ in order to eliminate crystal structure. Pure fat samples and 1:1 blend of PMF and animal fats were prepared in liquid state in volumetric flasks and then cooled to $5^{\circ} \mathrm{C}$ and kept in refrigerator until the measurements were conducted.

\subsection{Methods}

Fatty acid composition of pure fats was analysed by gas chromatography (GC) according to the methods based on ISO (1990a, b). The type of the apparatus was HP 5890 GC System, with SGE BPX 70 column with parameters: $50 \mathrm{~m}, 0.22 \mathrm{~mm}, 0.25 \mu \mathrm{m}$. Heating was from $150{ }^{\circ} \mathrm{C}$ to $210^{\circ} \mathrm{C}$ (with $1.3{ }^{\circ} \mathrm{C} \mathrm{min}-1$ heating rate). Pressure: 14 psi, injector: $250{ }^{\circ} \mathrm{C}$ split, split ratio: 100:1. FID detector: $250{ }^{\circ} \mathrm{C}$. Carrier gas: hydrogen, flow rate $0.6 \mathrm{~cm}^{3} \mathrm{~min}^{-1}$, injection pressure 0.965 bar. Identification of fatty acids was based on the retention times using fatty acid methyl ester standards.

Melting profile of the fats was established by the solid fat content curves (SFC) by means of pNMR apparatus (Bruker Minispec 300, Bruker, Germany) following the AOCS method (AOCS, 1999). The samples were heated to $80^{\circ} \mathrm{C}$ and held for $15 \mathrm{~min}$ in order to eliminate crystal memory. All samples were kept at $60{ }^{\circ} \mathrm{C}$ for $15 \mathrm{~min}$., cooled down to $0{ }^{\circ} \mathrm{C}$ and maintained at this temperature for $60 \mathrm{~min}$. Finally, before measurements, samples were held at the temperature of the measurements for $30-35 \mathrm{~min}$. Temperatures were: $5^{\circ} \mathrm{C}, 10^{\circ} \mathrm{C}$, $15{ }^{\circ} \mathrm{C}, 20{ }^{\circ} \mathrm{C}, 25{ }^{\circ} \mathrm{C}, 30{ }^{\circ} \mathrm{C}, 35^{\circ} \mathrm{C}$, and $40^{\circ} \mathrm{C}$. Three parallel measurements were done and average values were reported. SFC curves served as means of monitoring the miscibility of the fats. If SFC lines cross each other, the crosspoint should be considered as the eutectic point. In that case the fats are incomparable in a 1:1 ratio.

Crystallization was detected by DSC Setaram 131 evo apparatus. Measurements followed the method developed by LAI and co-workers (1998) with slight modifications. The melted fat sample was dropped into the sample holder (cca 20-25 mg) and kept at ambient temperature overnight. Samples were cooled down to $0{ }^{\circ} \mathrm{C}$ by $1{ }^{\circ} \mathrm{C} \min ^{-1}$ and kept at this temperature for $10 \mathrm{~min}$. Heating scenario was performed as follows: heating ratio was $1{ }^{\circ} \mathrm{C}$ $\mathrm{min}^{-1}$ until the temperature reached $80{ }^{\circ} \mathrm{C}$. At $80{ }^{\circ} \mathrm{C}$ the samples were kept for $30 \mathrm{~min}$. The cooling scenario started after this stay and cooling speed was $1^{\circ} \mathrm{C} \mathrm{min}^{-1}$ until the temperature reached $-20^{\circ} \mathrm{C}$. Before heating again to ambient temperature, the samples were held at this temperature for $10 \mathrm{~min}$. After that the heating began with the speed of $5{ }^{\circ} \mathrm{C} \mathrm{min}^{-1}$ up to $20^{\circ} \mathrm{C}$ and the calorimetric measurement ended. Three parallel measurements were done and the typical thermogram was chosen for reporting.

Isotherm crystallization was detected by measuring solid fat content with pNMR (Bruker Minispec 120) apparatus. The measurement had been based on the method reported by CAmpos and co-workers (2010) and was modified as follows: Samples were heated up to 80 ${ }^{\circ} \mathrm{C}$ and kept there for $15 \mathrm{~min}$. The completely liquid samples were transferred to NMR tubes and put into a $5{ }^{\circ} \mathrm{C}$ thermostat. Measurements were done every 5 min for $6 \mathrm{~h}$. Three parallel measurements had been done and average values were reported. 


\section{Results and discussion}

\subsection{Fatty acid composition of pure fats and blends}

Samples were characterized by their fatty acid composition. Results are summarized in Table 1. Dominant fatty acids in PMF were palmitic (46.2\%) and oleic (39.4\%) acids. Stearic acid was present at $9.1 \%$. Minor amounts of some saturated and unsaturated fatty acids were also detectable. AMF contained fatty acids in a great variety. Dominant fatty acids were palmitic, oleic, and stearic acids. These three covered $65 \%$ of the total. Short and medium chain fatty acids were present in the remaining $35 \%$, of those butyric acid, capric acid, lauric acid, and myristic acid were substantial. Small amounts of trans fatty acids were also detected since these are a natural component of the milk. Odd number fatty acids were found in AMF in $2.5 \%$. The other animal fats contained these in negligible amounts. $G$ had polyunsaturates (more than 10\%) and saturates (close to $30 \%$ ). L showed a similar fatty acid profile to G, but the total amount of the saturated fatty acids was higher $(37.7 \%)$.

Table 1. Fatty acid composition (\%) of the investigated pure fats

\begin{tabular}{|c|c|c|c|c|}
\hline & \multicolumn{4}{|c|}{ Fatty acid composition $(\%)$} \\
\hline & $\mathrm{AMF}$ & Goose & Lard & PMF \\
\hline C4:0 & 1.9 & 0.0 & 0.0 & 0.0 \\
\hline C6:0 & 1.5 & 0.0 & 0.0 & 0.0 \\
\hline C8:0 & 1.1 & 0.0 & 0.0 & 0.0 \\
\hline C10:0 & 2.8 & 0.0 & 0.1 & 0.0 \\
\hline C10:1 & 0.3 & 0.0 & 0.0 & 0.0 \\
\hline $\mathrm{C} 12: 0$ & 4.2 & 0.0 & 0.1 & 0.2 \\
\hline $\mathrm{C} 12: 1$ & 0.1 & 0.0 & 0.0 & 0.0 \\
\hline $\mathrm{C} 13: 0$ & 0.1 & 0.0 & 0.0 & 0.0 \\
\hline $\mathrm{C} 13: 1$ & 0.1 & 0.0 & 0.0 & 0.0 \\
\hline $\mathrm{C} 14: 0$ & 12.5 & 0.6 & 1.3 & 1.1 \\
\hline $\mathrm{C} 14: 1$ & 1.4 & 0.0 & 0.0 & 0.1 \\
\hline $\mathrm{C} 15: 0$ & 1.2 & 0.0 & 0.0 & 0.0 \\
\hline C15:1 & 0.3 & 0.0 & 0.0 & 0.0 \\
\hline $\mathrm{C} 16: 0$ & 34.8 & 22.7 & 23.1 & 46.2 \\
\hline $\mathrm{C} 16: 1 \mathrm{tr}$ & 0.00 & 0.73 & 0.00 & 0.00 \\
\hline $\mathrm{C} 16: 1 \mathrm{cis}$ & 1.7 & 3.6 & 2.4 & 0.1 \\
\hline $\mathrm{C} 17: 0$ & 0.6 & 0.1 & 0.3 & 0.1 \\
\hline C17:1 & 0.2 & 0.1 & 0.3 & 0.0 \\
\hline
\end{tabular}


Table 1. cont.

\begin{tabular}{|c|c|c|c|c|}
\hline & \multicolumn{4}{|c|}{ Fatty acid composition (\%) } \\
\hline & AMF & Goose & Lard & PMF \\
\hline C18:0 & 10.7 & 7.1 & 13.1 & 9.1 \\
\hline $\mathrm{C} 18: 1 \mathrm{tr}$ & 0.53 & 0.33 & 0.00 & 0.65 \\
\hline $\mathrm{C} 18: 1$ is & 19.0 & 53.7 & 44.5 & 39.4 \\
\hline $\mathrm{C} 18: 2 \operatorname{tr}$ & 0.82 & 0.25 & 0.00 & 0.85 \\
\hline $\mathrm{C} 18: 2$ cis & 1.4 & 9.7 & 11.9 & 1.4 \\
\hline $\mathrm{C} 18: 3 \mathrm{tr}$ & 0.00 & 0.00 & 0.00 & 0.00 \\
\hline $\mathrm{C} 18: 3$ cis & 0.4 & 0.4 & 0.7 & 0.4 \\
\hline $\mathrm{C} 20: 0$ & 0.5 & 0.1 & 0.0 & 0.0 \\
\hline $\mathrm{C} 20: 1$ & 0.1 & 0.2 & 1.1 & 0.0 \\
\hline $\mathrm{C} 20: 2$ & 0.0 & 0.0 & 0.6 & 0.0 \\
\hline $\mathrm{C} 22: 0$ & 0.0 & 0.0 & 0.0 & 0.0 \\
\hline $\mathrm{C} 22: 1$ & 0.0 & 0.0 & 0.0 & 0.0 \\
\hline $\mathrm{C} 24: 0$ & 0.1 & 0.1 & 0.0 & 0.2 \\
\hline $\mathrm{C} 24: 1$ & 0.0 & 0.0 & 0.0 & 0.0 \\
\hline not id. & 1.6 & 0.3 & 0.6 & 0.2 \\
\hline Sum & 100.0 & 100.0 & 100.0 & 100.0 \\
\hline Sum trans & 1.35 & 0.58 & 0.00 & 1.5 \\
\hline
\end{tabular}

\subsection{The effect of animal fats on the melting characteristics of PMF}

Melting characteristics of the samples are summarized in Figure 1. 1/A shows the SFC curves of PMF, AMF, and PMF/AMF blend; 1/B belongs to the SFC curves of PMF, L, and the blend of these; 1/C illustrates the SFC curves of PMF, G, and their blend. In Figure 1 it is observable that the curves of the blends run in between the pure fats. In each case PMF had the higher solid fat content at every temperature. SFC values of PMF/AMF blend were closer to AMF. $\mathrm{SFC}$ of $\mathrm{PMF} / \mathrm{L}$ was approximately the average of the pure fats. The position of $\mathrm{PMF} / \mathrm{G}$ curve was slightly closer to the curve of goose fat.

Melting was characterized by DSC thermograms obtained by heating the samples (Fig. 2). It is seen that PMF (curve $\mathrm{H}$ ) has an endothermic peak with a maximum at approximately $48{ }^{\circ} \mathrm{C}$. The maximum of the dominant endothermic peak of lard was located at $30^{\circ} \mathrm{C}$ (curve A), AMF showed two peaks, one at $15^{\circ} \mathrm{C}$ and another at $35^{\circ} \mathrm{C}$ (curve $\mathrm{C}$ ) (similarly to the findings of WiLliams and co-workers, 1997), and G had no characteristic peak, probably due to its poorly crystallised structure (curve E). PMF/AMF blend (curve D) showed two peaks: a bigger one at $42{ }^{\circ} \mathrm{C}$ and a smaller at about $13{ }^{\circ} \mathrm{C}$. The first part of the thermogram ran similarly to AMF's, probably due to the presence of short and medium chain fatty acids. The 

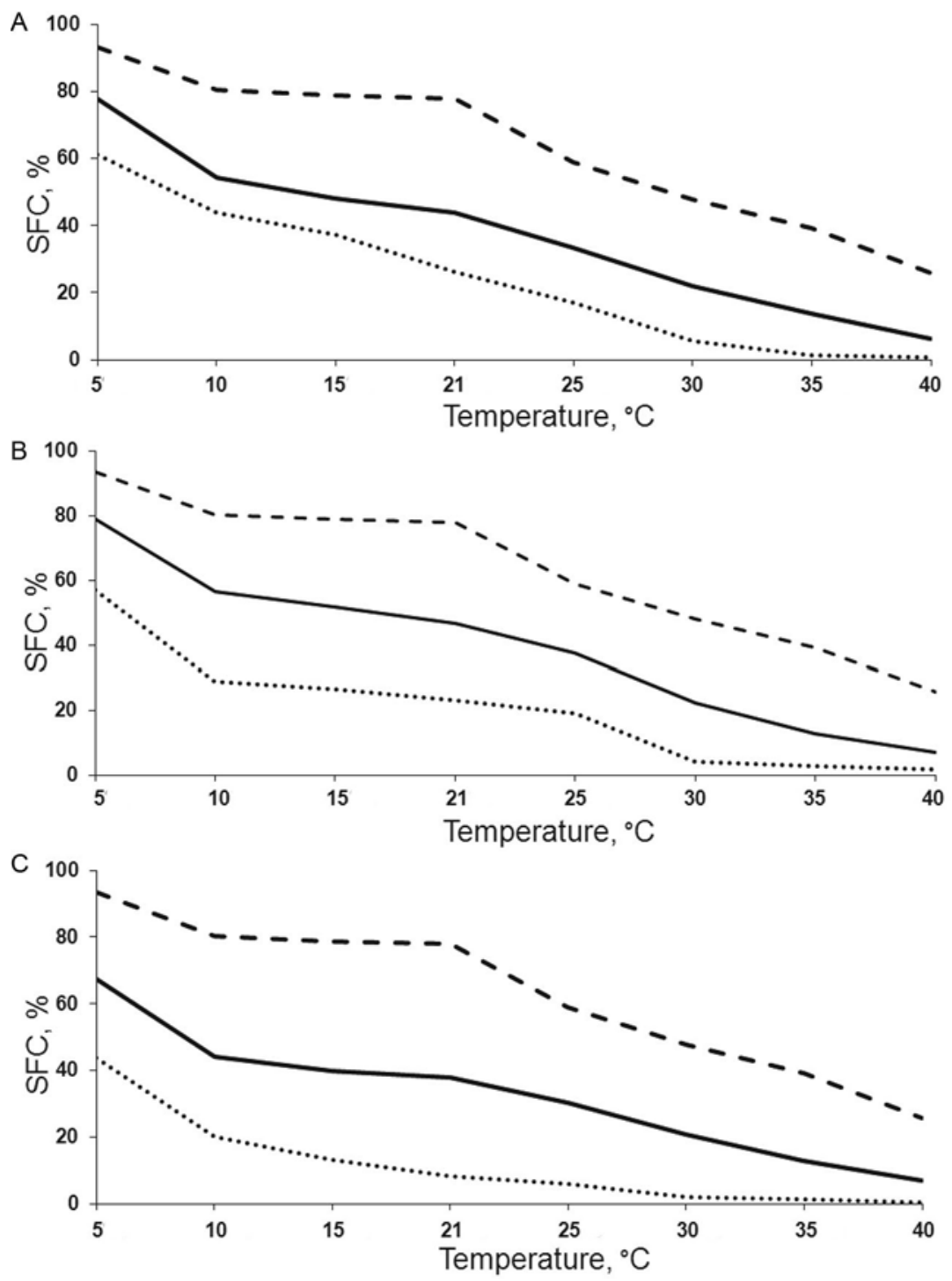

Fig. 1. SFC curves of pure fats and blends

A: PMF, AMF, and their blend, B: PMF, L, and their blend, C: PMF, G, and their blend. - - . - . - : PMF; ............ : animal fat; $\_$: blend

second segment was similar to the PMF's. PMF/L blend had one wide peak from $25^{\circ} \mathrm{C}$ to $47{ }^{\circ} \mathrm{C}$ with a maximum at $42{ }^{\circ} \mathrm{C}$ (curve B) and an additional peak also appeared (cca. at $15^{\circ} \mathrm{C}$ ). The bigger peak should be the result of coalescence of the majority of the crystals in the pure fats. In the melting thermogram of PMF/G blend (curve F) the endothermic peak appeared at a lower temperature: the maximum was at about $40^{\circ} \mathrm{C}$. This phenomenon implied that $\mathrm{G}$ had only a softening effect on PMF. 


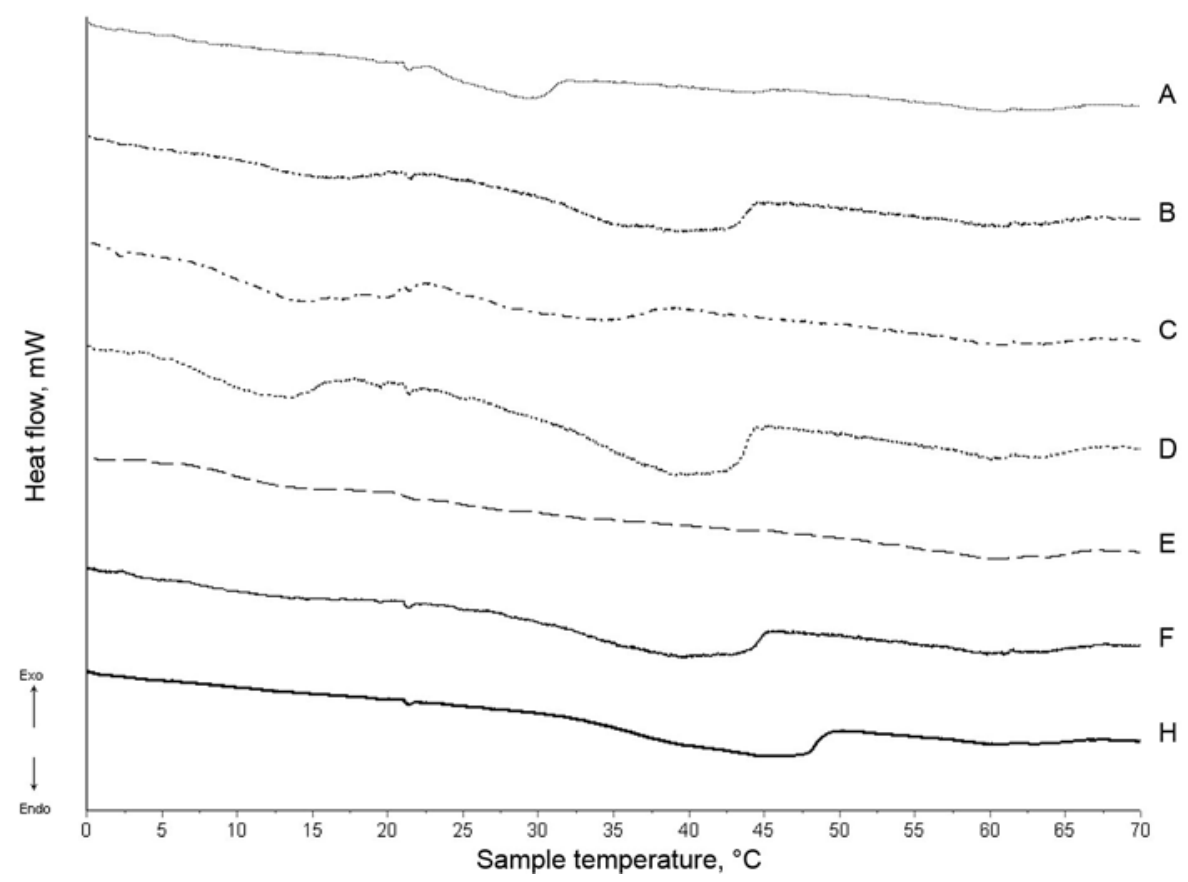

Fig. 2. Melting thermograms of PMF, animal fats, and their blends A: Lard ; B: Lard/PMF; C: AMF; D: AMF/PMF; E: Goose; F: Goose/PMF; H: PMF

\subsection{The effect of animal fats on the solidification of PMF}

Results of the isotherm crystallization of the samples are in Figure 3. 3/A demonstrates the isotherm crystallization of PMF, AMF, and their blend; 3/B illustrates the solidification process of PMF, lard, and their blend; 3/C shows the isotherm solidification of PMF, G, and their blend.

After 20 min PMF reached the equilibrium SFC value. AMF started to solidify very fast within the first five min, afterwards SFC changed moderately. Lard solidified fast, within the first ten min SFC almost completely reached the equilibrium. G solidified in a two-step way. The first phase was in the first $15 \mathrm{~min}$. The next phase lasted until the $35^{\text {th }}$ min and SFC reached the equilibrium at that point. Crystallization of the PMF/AMF blend was similar to AMF. The phenomenon manifested in two steps, a fast period in the beginning and a slow period in the next step. This finding was in accordance with the results of AIMI (2001), who proved the strong modification feature of AMF on melting of palm fat.

Solidification of the PMF/L blend differed from the parent fats. Equilibrium and individual SFC values of the blend were closer to PMF than to L. Solidification of PMF/G blend followed the way of PMF. The characteristic two-step solidification of G disappeared in the blend (Fig. 3/C). 

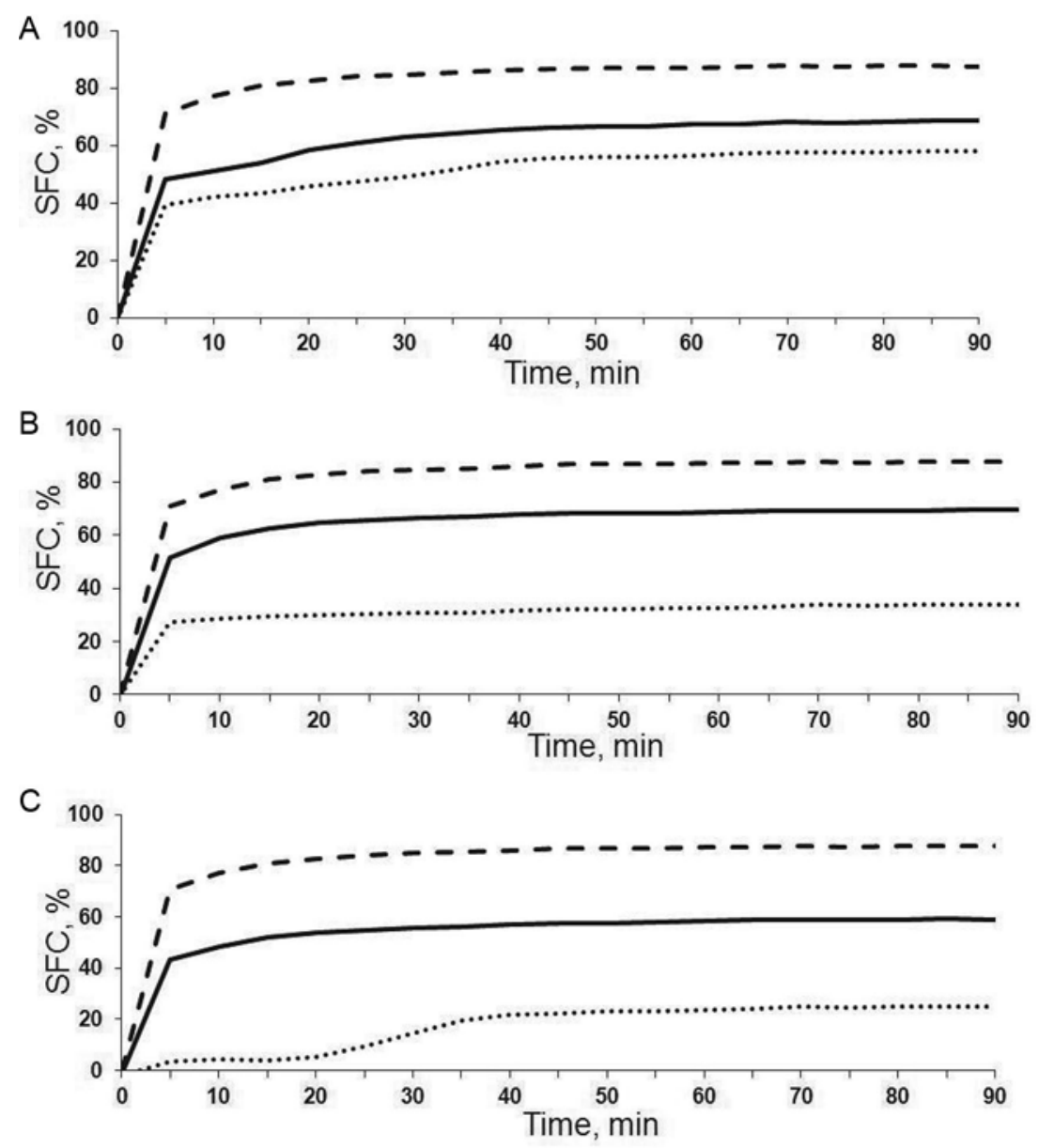

Fig. 3. Isotherm crystallization of pure fats and their blends A: PMF, AMF, and their blend; B: PMF, L, and their blend; C: PMF, G, and their blend. - - - - - : PMF; : animal fat; : blend

Thermograms of solidification obtained by DSC are shown in Figure 4. Isotherm crystallization of PMF performed a characteristic exothermic peak at about $28{ }^{\circ} \mathrm{C}$ within the measured temperature region (curve $\mathrm{H}$ ). Solidification of AMF showed more complexity (curve C). Two peaks were detectable, one at $17{ }^{\circ} \mathrm{C}$ and the other at $13{ }^{\circ} \mathrm{C}$. CAmpos and coworkers (2010) found the same phenomenon. The cooling process resulted in a big exothermic peak in L. A small shoulder was observable at about $22^{\circ} \mathrm{C}$. A similar curve was obtained by MARIKKAR and co-workers (2002). Curve E illustrates the solidification of G. Only one small peak was found, indicating a weak crystallization aptitude. PMF/AMF blend had two exothermic peaks (curve D). The bigger of those had a maximum at $24{ }^{\circ} \mathrm{C}$ and the smaller at $20^{\circ} \mathrm{C}$, indicating the presence of the characteristic crystals of AMF. Cooling of PMF/L (curve $\mathrm{B})$ resulted in three exothermic peaks, probably due to the interaction of the pure fats. The thermogram of $\mathrm{PMF} / \mathrm{G}$ showed one exothermic peak at $23{ }^{\circ} \mathrm{C}$. The shape and the height of the peak were almost the same as the peak of PMF. 


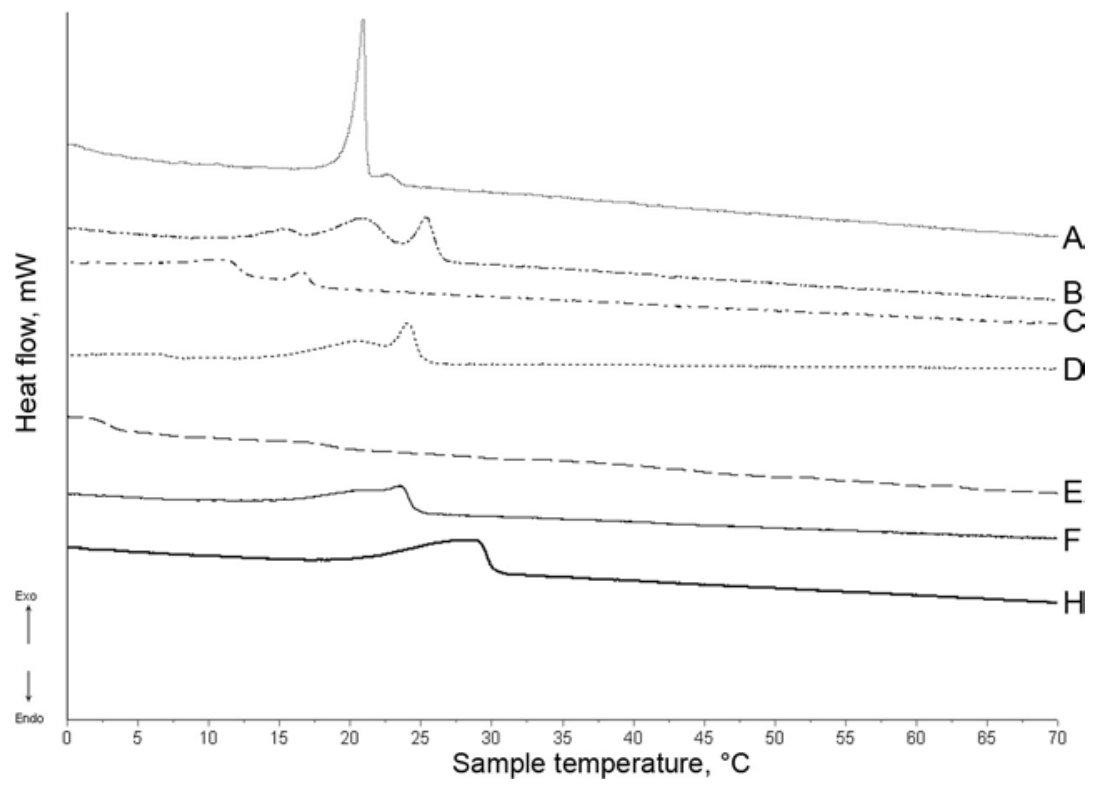

Fig. 4. Solidification thermograms of pure fats and their blends A: Lard; B: Lard/PMF; C: AMF; D: AMF/PMF; E: Goose; F: Goose/PMF; H:PMF

\section{Conclusions}

AMF sharply differed from PMF in melting and solidification properties. AMF tenderized PMF in the blend. Summarizing the effect of AMF on the physical properties of PMF it can be stated that the blend became similar to the AMF. It means that in the presence of AMF in a $50 \%$ of palm fat blend it modifies the melting and solidification properties towards the direction of AMF. Based on the results of our investigations it is clear that L softened the PMF. The presence of 50\% L in PMF causes an observable modification in melting and solidification properties. The blend should be considered as more tender than PMF, but has a different character. G softened the PMF, which was proven by our results. Summarizing the effect of $\mathrm{G}$ on melting and solidification, we could conclude that the characteristics of PMF remained the same but a definite softening impact of $G$ prevailed.

This work was supported by the TÁMOP 4.2.1./B09/01/KMR/2010-0005 project

\section{References}

Aimi, N. (2001): Effect of tempering on physical properties of shortenings based on binary blends of palm oil and anhydrous milk fat during storage. -in: Widlak, N., Hartel, R.W. \& Narine, S. (Eds) Crystallization and solidification properties of lipids. AOCS Press, Champaign, Illinois, pp. 42-52. 
AOCS (1999): AOCS official method Cd 16b-93 Solid fat content (SFC) by low-resolution nuclear magnetic resonance; -in: Official methods and recommended practices of the AOCS, The American Oil Chemists Society, Champaign, IL

Bell, A., Gordon, M.H., Jirasubrurakorn, W. \& Smith, K.W. (2007): Effect of composition on fat rheology and crystallization. Fd Chem., 101, 799-805.

Braipson-Danthine, S. \& Deroanne, C. (2004): Influence of SFC, microstructure and polymorphism on texture (hardness) of binary blends of fats involved in the preparation of industrial shortenings. Fd Res. Int., 37, 941-948.

Campos, R., Narine, S.S. \& Marangoni, A.G. (2010): Effect of cooling rate on the structure and mechanical properties of milk fat and lard. Fd Res. Int., 3, 971-981.

Danthine, S. (2012): Physical and structural properties of compound dairy fat blend. Fd Res. Int., 48, $187-195$.

ISO (1990a): Animal and vegetable fats and oils - Analysis by gas chromatography of methyl esters of fatty acids. ISO 5508:1990

ISO (1990b): Animal and vegetable fats and oils. Preparation of methyl esters of fatty acids. ISO 5509:1990 withdrawn

JiN, Q., ZhANG, T. \& SHAN, L. (2008): Melting and solidification properties of palm kernel oil, tallow and palm olein blends in the preparation of shortening. J. Am. Oil Chem. Soc., 85, 23-28.

Lai, O.M., Ghazali, H.M. \& Chond, C.L. (1998): Effect of enzymatic transesterification on the melting points of palm stearin-sunflower oil mixtures. J. Am. Oil Chem. Soc., 75, 881-886.

Liew, M.Y.B., Ghazali, H.M., Long, K., Lai, O.M. \& Yazid, A.M. (2001): Physical properties of palm kernel oleinanhydrous milk fat mixtures transesterified using mycelium-bound lipase from Rhizomucor miehei. Fd Chem., 72, 447-454.

Marikkar, J.M.N., Lai, O.M., Ghazali, H.M. \& Che Man, Y.B. (2002): Compositional and thermal analysis of RBD palm oil adulterated with lipase-catalyzed interesterified lard. Fd Chem., 76, 249-258.

Ming, L.O., Ghazali, H.M. \& Let, C.C. (1999): Use of enzymatic transesterified palm stearin-sunflower oil blends in the preparation of table margarine formulation. Fd Chem., 64, 83-88.

Singh, A.P., McClements, D.J. \& Marangoni, A.G. (2004): Solid fat content determination by ultra-sonic velocimetry. Fd Res. Int., 37, 545-555.

Williams, S.D., Ransom-Painter, K.L. \& Hartel, R.W. (1997): Mixtures of palm kernel oil with cocoa butter and milk fat in compound coating. J. Am. Oil Chem. Soc., 74(4), 357-366. 